\title{
Efficient and Air-Stable Mixed-Cation Lead Mixed-Halide Perovskite Solar Cells with n-Doped Organic Electron Extraction Layers
}

\author{
Zhiping Wang, David P. McMeekin, Nobuya Sakai, Stephan van Reenen, \\ Konrad Wojciechowski, Jay B. Patel, Michael B. Johnston, and Henry J. Snaith**
}

The discovery of organic-inorganic metal halide perovskite materials for applications in solar-energy conversion has sparked a tremendous research and development effort worldwide in both academia and industry. ${ }^{[1,2]}$ This attention is due to their extraordinary optoelectronic properties, such as long electron-hole diffusion lengths, ${ }^{[3]}$ tunable band gap, ${ }^{[4,5]}$ low recombination rate, ${ }^{[6]}$ solution processability, ${ }^{[7]}$ and potential low fabrication cost. ${ }^{[8]}$ In the past few years, perovskite solar cells have experienced an unprecedented development, achieving the highest certified power conversion efficiency (PCE) of $22.1 \%$ in a single-junction device. ${ }^{[9]}$ Although device efficiency now surpasses the record efficiency for mainstream multi-crystalline silicon, ${ }^{[10]}$ long-term stability, suitable to deliver greater than 25 years outdoor operation, remains to be proven. Both the perovskite absorber layer and the interfaces between the perovskite and the charge extraction layers can have a significant impact upon the long-term stability of the solar cell. ${ }^{[11-16]}$

All commercial solar modules are encapsulated in order to enable 25 years of operation. Silicon modules have historically been encapsulated with a polymer back sheet laminated with a hot-melt polymer foil to a glass front sheet, and are moving toward glass-glass laminates to deliver improved stability. Thin-film modules, such as copper indium gallium (di)selenide, generally employ both a lamination foil and more robust polymer edge sealing to deliver a stable glass-glass laminated module. ${ }^{[17]}$ However, the more robust the cell technology is to environmental degradation, the less elaborate the environmental encapsulation will need to be, and hence the less costly the production. The target for perovskite solar cells is therefore to become robust enough to be compatible with conventional thin-film glass-glass laminate encapsulation technologies. ${ }^{[17]}$ For that purpose, focusing on enhancing the stability of the perovskite materials and devices under accelerated environmental stressing in air will force continued improvement of the perovskite solar cells to environmental degradation.

To improve the air stability of the devices, various $n$ and p-type interface materials have been developed aiming to

Dr. Z. Wang, D. P. McMeekin, Dr. N. Sakai,

Dr. S. van Reenen, Dr. K. Wojciechowski,

J. B. Patel, Prof. M. B. Johnston, Prof. H. J. Snaith

Clarendon Laboratory

Department of Physics

University of Oxford

Parks Road, Oxford OX1 3PU, UK

E-mail: henry.snaith@physics.ox.ac.uk

DOI: 10.1002/adma.201604186 protect the perovskite absorber layer from exposure to moisture, oxygen, and UV light. ${ }^{[18-20]}$ Recently, Yang and co-workers demonstrated that inorganic metal oxides can be employed as interfacial materials to enhance the air stability. ${ }^{[18]}$ Bryant et. al. show that this light and oxygen induced degradation of perovskite solar cells can be slowed down by the use of interlayers that extract electrons from the perovskite film before they can react with oxygen. ${ }^{[21]}$ Organic charge collection layers, such as fullerenes, have been shown to enable highly effective electron extraction when interfaced with the perovskite absorbers ${ }^{[22-24]}$ and reduce UV-induced degradation of the solar cell in comparison with devices employing inorganic $\mathrm{TiO}_{2} \cdot{ }^{[22]}$ The use of organic layers also facilitates fabricating the entire solar cell at low temperatures (no need for the high temperature sintering step required to obtain highly crystalline metal oxide layers), suitable for processing involving temperature sensitive substrates, including flexible plastic foil and for silicon solar cells. ${ }^{[22]}$ However, compared with their inorganic metal oxide counterparts, organic semiconductors are prone to degradation in water, oxygen, and UV light themselves. ${ }^{[18]}$ One strategy for circumventing this problem with organic charge extraction layers is to utilize air-stable dopants that increase the density of mobile charge to compensate for the trapped charge, which could be generated under operation, i.e., with the presence of $\mathrm{O}_{2}, \mathrm{H}_{2} \mathrm{O} \cdot{ }^{[25]}$ Although p-type dopants are used universally in perovskite solar cells, there are very few reports on $n$-doping of the electron collection layers. For fullerene derivatives and other organic n-type charge conductors, dihydro-1H-benzoimidazol-2-yl ( $N$-DBI) derivatives have been established as airstable n-type dopants. ${ }^{[25-27]}$ It has been reported that $N$-DBI doping can improve the air stability of $n$-channel organic field effect transistors. ${ }^{[25,28]}$ 3-dimethyl-2-phenyl-2,3-dihydro1 H-benzoimidazole ( $N$-DMBI) has also been used to $n$-dope phenyl- $\mathrm{C}_{61}$-butyric acid methyl ester in an inverted structure. ${ }^{[29]}$ However, after film deposition, the dopant must be activated via overnight thermal annealing in an inert atmosphere after film deposition. ${ }^{[25-27]}$ This long annealing process is incompatible with the $\mathrm{CH}_{3} \mathrm{NH}_{3} \mathrm{PbI}_{3}$ inverted architecture due to thermal degradation of the perovskite.

Herein, we demonstrate "air-stable" doping of the n-type $\mathrm{C}_{60}$ electron extraction layer in an $\mathrm{n}-\mathrm{i}-\mathrm{p}$ planar heterojunction perovskite device and show enhanced device efficiency with improved long-term device stability under simulated full spectrum sun light. Using the $\mathrm{n}$-doped $\mathrm{C}_{60}$ charge collection layer, we achieved a current-density voltage $(J-V)$ determined power conversion efficiency of $18.3 \%$ (with a stabilized efficiency of $17.6 \%$ ) and improved device stability in 
the mixed halide $\mathrm{CH}_{3} \mathrm{NH}_{3} \mathrm{PbI}_{x} \mathrm{Cl}_{3-x}$ system. We also present the first long-term stability study of the new "mixed-cation mixed-halide" perovskite composition $\left.\mathrm{FA}_{0.83} \mathrm{Cs}_{0.17} \mathrm{~Pb}_{\left(\mathrm{I}_{0.6}\right.} \mathrm{Br}_{0.4}\right)_{3}$ $\left(\mathrm{FA}=\left(\mathrm{HC}\left(\mathrm{NH}_{2}\right)_{2}\right)\right)$ and discover that the cells are remarkably stable when exposed to full spectrum simulated sun light in ambient conditions without encapsulation. We find that the nonencapsulated devices comprising the n-doped $\mathrm{C}_{60}$ layer with the $\mathrm{FA}_{0.83} \mathrm{Cs}_{0.17} \mathrm{~Pb}\left(\mathrm{I}_{0.6} \mathrm{Br}_{0.4}\right)_{3}$ absorber layer sustain $80 \%$ of their "post burn-in" efficiency after $650 \mathrm{~h}$ stressing under full sun illumination in ambient conditions, and over $3400 \mathrm{~h}$ when sealed in a glass-glass laminate. The air stability is more than a 30-fold improvement over comparable state-of-the-art $\mathrm{CH}_{3} \mathrm{NH}_{3} \mathrm{PbI}_{x} \mathrm{Cl}_{3-x}$ devices, highlighting the significance of this achievement.

We have previously shown that the compact $\mathrm{TiO}_{2}$, often employed in planar heterojunction perovskite solar cells, induces an accelerated degradation when the cells are exposed to full spectrum sun light. ${ }^{[22,30]}$ Here we therefore focus our efforts on employing $\mathrm{C}_{60}$ as the $\mathrm{n}$-type charge collection layer. We first investigate the influence of $n$-doping of the $\mathrm{C}_{60}$ layer. Compared with its parent N-DMBI, 4-(1,3-dimethyl-2,3-dihydro1 H-benzimidazol-2-yl)- $N, N$-diphenylaniline ( $N$-DPBI) has a decreased electron-donating strength of the amine functionality by a substitution of methyl groups with phenyl rings. ${ }^{[31]}$ The aromatic phenyl rings stabilize the radical species through resonance, ensuring a stable doped formulation over time. We dissolved $\mathrm{N}$-DPBI and $\mathrm{C}_{60}$ in dichlorobenzene and spin-coated the solution in a nitrogen-filled glove box directly on glass or fluorine doped tin oxide (FTO) coated glass to form a thin film. To activate the doping, we thermally annealled all the asdeposited films on a hotplate for $12 \mathrm{~h}$ at $80{ }^{\circ} \mathrm{C}$ in a nitrogen atmosphere. Through this thermal-activation process, a reaction between the $N$-DPBI dopant and host $\mathrm{C}_{60}$ would lead to the formation of $\mathrm{C}_{60}$ radical anions, which is responsible for the doping effect. ${ }^{[26,27]}$ To evaluate the $n$-type doping ability of $N$-DPBI, we measured the conductivity of neat (control) and doped $\mathrm{C}_{60}$ films on glass in air, as we show in Figure 1b. As expected for successful extrinsic doping, the conductivity of the $\mathrm{C}_{60}$ film increased by more than three orders of magnitude from $6 \times 10^{-6} \mathrm{~S} \mathrm{~cm}^{-1}$ with neat $\mathrm{C}_{60}$ to $9 \times 10^{-3} \mathrm{~S} \mathrm{~cm}^{-1}$ with $1 \mathrm{wt} \%(\approx 2 \mathrm{~mol} \%) \mathrm{N}$-DPBI doping. We observe further evidence for $n$-doping by measuring a reduction in the work function of $\mathrm{C}_{60}$ films coated on FTO substrates when the $\mathrm{C}_{60}$ is doped with $N$-DPBI (Figure $1 \mathrm{~b}$ and details in the Supporting Information), which is in close agreement with previous studies, which have used ultraviolet photoemission spectroscopy to confirm $n$-doping of $\mathrm{C}_{60} \cdot{ }^{[2,32]}$ As we show in Figure $\mathrm{S} 1$ in the Supporting Information, with exposure of the doped $\mathrm{C}_{60}$ films to air, we do not observe significant decreases in conductivity over time, which indicates the excellent air stability of the doping. (a)

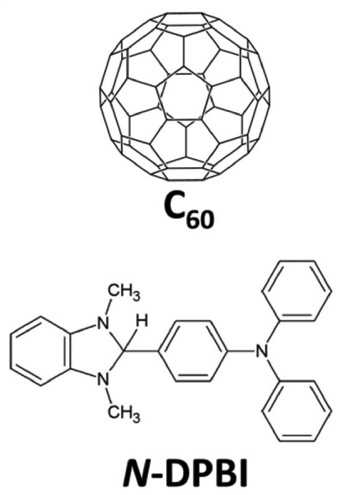

(b)

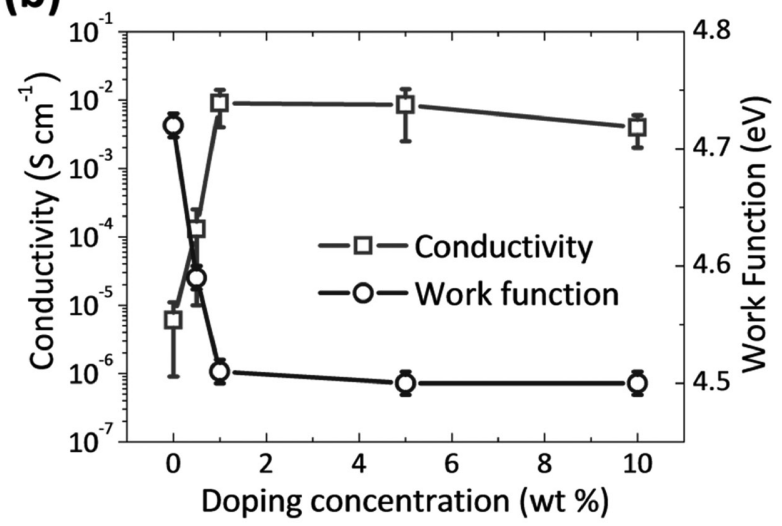

(c) Control
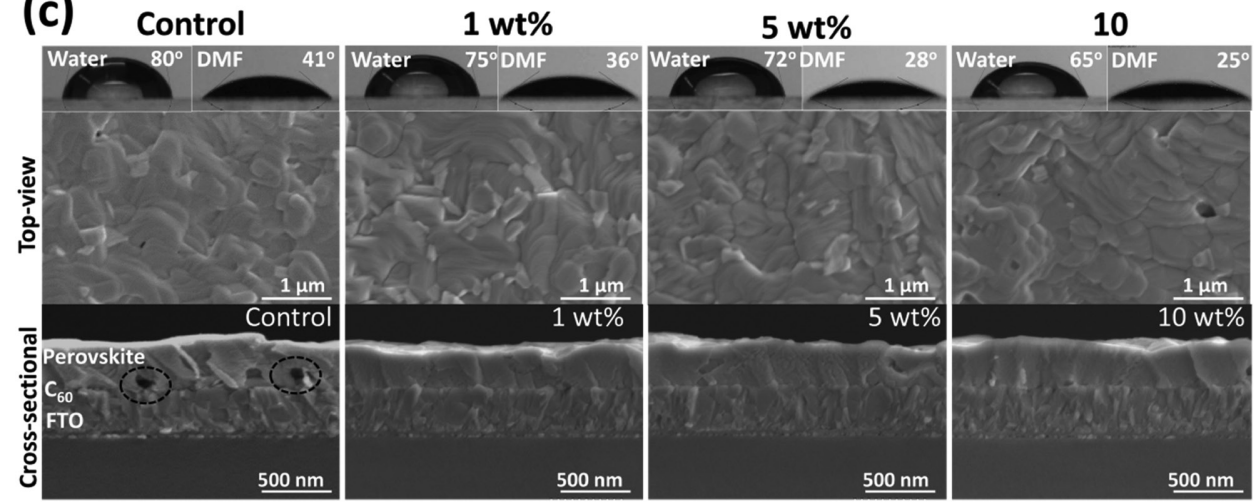

Figure 1. a) Chemical structures of $\mathrm{C}_{60}$ and n-type dopant $N$-DPBI molecules; b) conductivity and Kelvin-probe measurement of neat and $N$-DPBIdoped $\mathrm{C}_{60}$ films at different doping concentrations; $\mathrm{c}$ ) top-view and cross-sectional SEM images of perovskite films deposited on neat (control) and $N$-DPBI doped $\mathrm{C}_{60}$ films. The images on top show contact angle measurement of water and DMF on control and doped $\mathrm{C}_{60}$ films. The circles highlight interfacial voids/defects. 
At a higher doping concentration of $10 \mathrm{wt} \%(\approx 20 \mathrm{~mol} \%)$, we observe the conductivity decreasing slightly to $4 \times 10^{-3} \mathrm{~S} \mathrm{~cm}^{-1}$. This is likely due to inhomogeneous mixing of the dopant and $\mathrm{C}_{60}$ molecules at higher doping concentrations, as has been previously postulated. ${ }^{[27,33,34]}$ We show atomic force microscopy images of doped $\mathrm{C}_{60}$ films in Figure $\mathrm{S} 2$ in the Supporting Information, which are consistent with this notion.

To examine if there is any impact of $N$-DPBI doping on the $\mathrm{C}_{60}$ layer upon the microstructure of perovskite films subsequently deposited, we employ scanning electron microscopy (SEM) to characterize the top and cross-sectional morphology of perovskite films deposited on neat (control) and doped $\mathrm{C}_{60}$ films. All perovskite films display no conspicuous differences in topology with pinhole-free surfaces. However, in the crosssectional images we observe dark regions that we interpret to be vacancies/voids at or close to the perovskite/neat $\mathrm{C}_{60}$ interface, which we highlight with circles in Figure 1c (also see Figure S3 in the Supporting Information). We note that these voids do not appear to traverse the films in the form of complete pin-holes. Surprisingly, we find that upon doping the $\mathrm{C}_{60}$, these interfacial voids disappear, the absence of which is apparent in Figure 1c. To further understand this effect, we show the contact angle of water and $N, N$-dimethylformamide (DMF) on neat and doped $\mathrm{C}_{60}$ films in the insets of Figure 1c. The contact angle gradually decreases with increasing doping concentration. It seems that the incorporation of $\mathrm{N}$-DPBI dopant into $\mathrm{C}_{60}$ increases the wettability of the $\mathrm{C}_{60}$ film, which could be due to the increased surface energy of $\mathrm{C}_{60}$ films in the presence of triphenyl rings in $N$-DPBI dopant molecules. ${ }^{[35-37]}$ In Figure S4 in the Supporting Information we show X-ray diffraction (XRD) patterns of the perovskite films deposited on neat and doped $\mathrm{C}_{60}$ substrates. All the perovskite films crystallize into a typical tetragonal crystal structure, as reported previously. ${ }^{[2]}$ In the low doping regime ( $1 \mathrm{wt} \%)$, we observe an increased XRD peak intensity as compared with the perovskite film coated upon the neat $\mathrm{C}_{60}$ film. This could originate from the disappearance of the interfacial voids/defects. In comparison with the control perovskite film, we observe similar XRD peak width for the films processed on $1 \mathrm{wt} \%$ doped $\mathrm{C}_{60}$, while the peak width of the perovskite films processed on 5 and $10 \mathrm{wt} \%$ doped $\mathrm{C}_{60}$ is significantly broadened, indicative of a reduced crystallinity. ${ }^{[38]} \mathrm{A}$ recent study comparing different p-type organic hole conductors used in inverted $\mathrm{p}-\mathrm{i}-\mathrm{n}$ perovskite solar cells suggests that relatively nonwetting/hydrophobic substrates facilitate larger crystalline domain growth of the perovskite layers. ${ }^{[39]}$ We observe similar results here, where increasing the hydrophilic nature of the $\mathrm{C}_{60}$ film by doping has led to reduced XRD peak intensity and broadening of the peak width, which we interpret to indicate lower crystallinity in the perovskite films. ${ }^{[38,40]}$ However, as we previously noted, the neat $\mathrm{C}_{60}$ film appears to be too hydrophobic, resulting in void formation at the perovskite $\mathrm{C}_{60}$ interface. Therefore, the ideal compromise morphologically is for the system to contain a small concentration of $N$-DPBI in the $\mathrm{C}_{60}$, which we observe to effectively eliminate voids at the $\mathrm{C}_{60}$ / perovskite interface without sacrificing film crystallinity.

On contact with charge transport layers, perovskite films typically exhibit strong photoluminescence (PL) quenching, which we interpret to indicate efficient charge transfer from the photoactive layer to the transport layer. ${ }^{[18]}$ To investigate $N$-DPBI doping effects on interfacial electron transfer dynamics, we perform steady-state and time-resolved photoluminescence (TRPL) measurements on glass/perovskite, glass/(neat or doped $\mathrm{C}_{60}$ )/perovskite samples, as we show in Figure 2 and Figure S5 in the Supporting Information. We observe highly efficient quenching of the PL in the steady-state PL spectra of perovskite films coated on $\mathrm{C}_{60}$, indicating fast electron transfer from perovskite to $\mathrm{C}_{60}$, which is consistent with our previous studies. ${ }^{[23,24]}$ When coating the perovskite films upon $1 \mathrm{wt} \% \mathrm{~N}$-DPBI doped $\mathrm{C}_{60}$ films, the PL emission of the perovskite film is even more significantly quenched. For the TRPL decays, we observe a significantly faster PL decay for the films coated upon $1 \mathrm{wt} \% \mathrm{~N}$-DPBI doped $\mathrm{C}_{60}$. With excessive $N$-DPBI doping (5 and $10 \mathrm{wt} \%$ ), we notice a reduction in PL quenching for both steady-state and TRPL (Figure S5, Supporting Information), indicating less efficient electron extraction at the perovskite- $\mathrm{C}_{60}$ interface. In summary, it appears that a small amount of $N$-DPBI doping renders a higher conductivity of the n-type $\mathrm{C}_{60}$ layer, shifts the Fermi level in the $\mathrm{C}_{60}$ closer to vacuum, improves physical contact with the perovskite layer, and enables faster electron extraction, all of which should be favorable for solar cell operation.

To assess if the $N$-DPBI doped $\mathrm{C}_{60}$ can enhance solar cell performance, we have fabricated and optimized devices based on the $n-\mathrm{i}-\mathrm{p}$ planar heterojunction architecture glass $/ \mathrm{FTO} / \mathrm{C}_{60}$
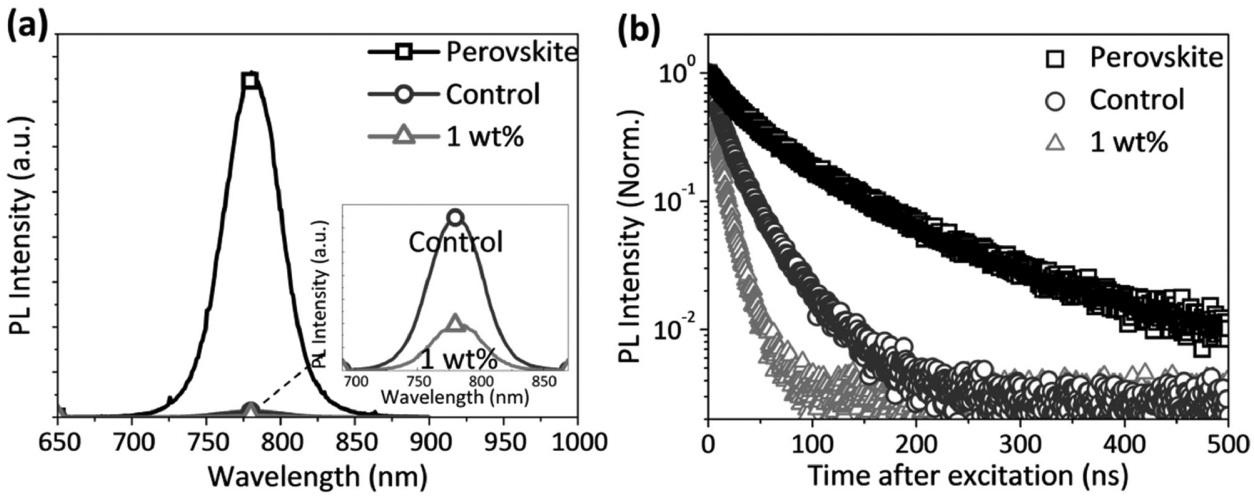

Figure 2. a) Steady-state and b) time-resolved photoluminescence (PL) spectra of perovskite films deposited on neat (control) and 1 wt $\%$ N-DPBI doped $\mathrm{C}_{60}$ coated glass substrate. The inset in (a) is a magnification of the PL spectra. 
(a)

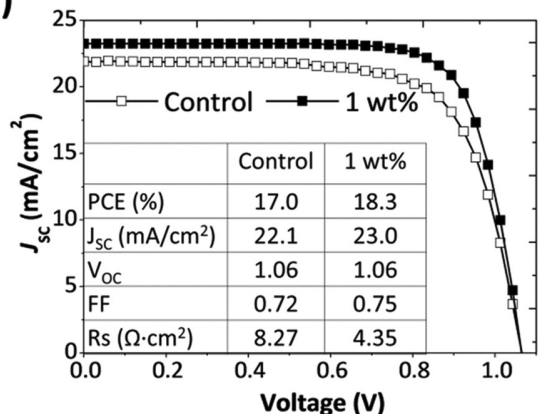

(c)

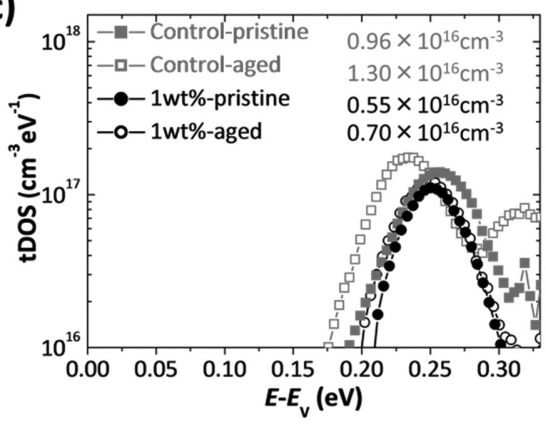

(b)

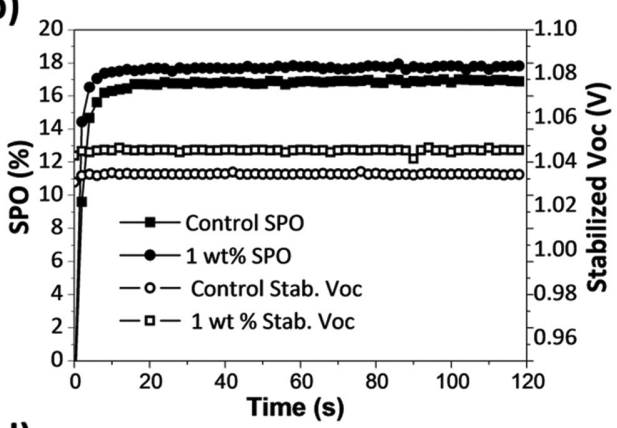

(d)

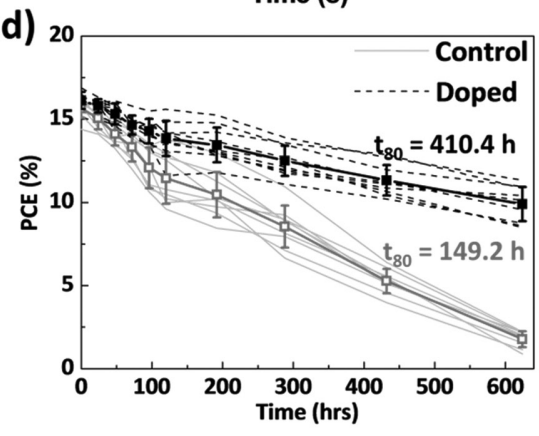

Figure 3. a) $\mathrm{J}-V$ characteristics of optimized perovskite solar cells with neat (control) and 1 wt\% $\mathrm{N}$-DPBI doped $\mathrm{C}_{60}$ layers, measured from forward bias to short circuit; the device configuration is FTO/C 60 (neat or doped) $/ \mathrm{CH}_{3} \mathrm{NH}_{3} \mathrm{PbI}_{x} \mathrm{Cl}_{3-x} /$ spiro-OMeTAD (doped with Li-TFSI and $t \mathrm{BP}$ )/Au. b) SPO of the champion cells by holding the cell at a fixed voltage near the maximum power point on the $J-V$ curve for $120 \mathrm{~s}$, and stabilized $V_{\text {oc }}$ measured by holding at open-circuit conditions without a voltage scan. c) Defect energy distribution within complete perovskite solar cells with neat (control) and 1 wt\% N-DPBI doped $\mathrm{C}_{60}$ electron-transporting layers (1 wt\%) both before (pristine) and after aging (aged) for $25 \mathrm{~d}$ in a dry desiccator in air without encapsulation, as indicated in the figure legend. The integrated trap density is $0.96 \times 10^{16} \mathrm{~cm}^{-3}$ (control-pristine), $1.30 \times 10^{16} \mathrm{~cm}{ }^{-3}$ (control-aged), $0.55 \times 10^{16} \mathrm{~cm}^{-3}$ (1 wt\%-pristine), and $0.70 \times 10^{16} \mathrm{~cm}^{-3}$ (1 wt\%-aged). d) Aging for $624 \mathrm{~h}$ of encapsulated high-performance perovskite solar cells with neat (control) and $1 \mathrm{wt} \% \mathrm{~N}$-DPBI doped $\mathrm{C}_{60}$ electron-transporting layers under full spectrum simulated $\mathrm{AM} 1.5,76 \mathrm{~mA} \mathrm{~cm}^{-2}$ irradiance at $V_{\text {Oc }}$ without a UV filter at $\approx 53{ }^{\circ} \mathrm{C}$. The time to $80 \%$ of the decay $\left(t_{80}\right)$ of champion devices is shown on the graph (with the $t_{0}$ efficiency extrapolated back to the $y$-axis from the linear fit).

(neat or doped)/perovskite $\left(\mathrm{CH}_{3} \mathrm{NH}_{3} \mathrm{PbI}_{3} \mathrm{Cl}_{3-x}\right)$ /spiro-OMeTAD/ Au. In Figure 3 we show $J-V$ characteristics of champion devices under simulated 1 sun AM1.5G $\left(100 \mathrm{~mW} \mathrm{~cm}{ }^{-2}\right)$ irradiance and give the full performance statistics of the entire device population in Figure S6 in the Supporting Information. With $N$-DPBI doped $\mathrm{C}_{60}$, the champion device exhibits a $J_{\mathrm{SC}}$ of $23 \mathrm{~mA} \mathrm{~cm}^{-2}$, a fill factor (FF) of 0.75 , and a $V_{\text {oc }}$ of $1.06 \mathrm{~V}$, yielding a power conversion efficiency of $18.3 \%$. In contrast to the control device (i.e., with neat $\mathrm{C}_{60}$ ), the enhancement is mainly due to improved $J_{\mathrm{SC}}$ and FF (also see Figure S6 in the Supporting Information). Additionally, we observe an almost $30 \%$ reduction in series resistance $\left(R_{\mathrm{S}}\right),{ }^{[41]}$ which can be attributed to the enhanced conductivity of the doped $\mathrm{C}_{60}$ layer or improved electronic contact at the $\mathrm{C}_{60}-\mathrm{FTO}$ interface. ${ }^{[42]}$ In Figure S18 in the Supporting Information, we show the reverse dark current of the pristine and doped devices. Since we do not observe a significant reduction in the dark current density at low applied biases with doping, we do not expect the voids observed from SEM images to propagate through the film in the form of pin-holes. Rather that indicates poorer physical contact between the perovskite and the $\mathrm{C}_{60}$ at this heterojunction. The $J-V$ measured efficiency $J_{\mathrm{sc}}$ and $V_{\mathrm{oc}}$ is artificially inflated by the anomalous hysteresis phenomena, whereby ionic species can migrate to the interfaces and modulate the trap-assisted recombination. ${ }^{[15]}$ To avoid this issue, we determined the stabilized power output (SPO) ${ }^{[13]}$ by measuring the current at a fixed maximum power point voltage over time. We observed a substantial increase in SPO from $16.2 \%$ to $17.9 \%$ for cells with and without doping, as we show in Figure $3 \mathrm{~b}$ along with statistics in Figure S6 in the Supporting Information. We also calculated the ratio between the $J-V$ measured efficiency and the SPO. We find the "SPO ratio" is closer to one for doped devices, implying a reduction in the trap-assisted recombination site density. ${ }^{[19]}$ We would expect a lower trap density to also deliver an increase in $V_{\text {oc }}$, which we do not observe in the measured $J-V$ curves. However, in Figure $3 \mathrm{~b}$ we also show the $V_{\text {oc }}$ over measured over time, where we observe that the $V_{\text {oc }}$ of the cell containing doped $\mathrm{C}_{60}$ is higher than the $V_{\text {oc }}$ of the control cell. Previous studies suggest that electron accumulation, arising from inefficient charge transfer at perovskite interfaces, exaggerates current voltage hysteresis and that the main origin is a combination of both defect sites responsible for trap-assisted recombination and mobile ionic species. ${ }^{[13,15,16]} \mathrm{C}_{60}$ or other fullerene derivatives are already known to be able to effectively passivate or inhibit the formation of defect states at the perovskite surface. ${ }^{[43,44]}$ It may be that the $n$-doping of $\mathrm{C}_{60}$ further assists, by reducing the density of "vacant" trap sites in the perovskite absorber layer in the vicinity of this interface, by inducing electron accumulation within the perovskite film in this region by surface charge transfer.

To quantify the effect of doping on the defect energy distribution in the active layer of the device, we carried out thermal 
admittance spectroscopy (TAS) measurements following procedures described in refs. ${ }^{[45,46]}$ and in the Supporting Information, and we show the results in Figure 3c. We find for all the devices studied a broad spectrum in the trap density of states exists, with a maximum between 0.23 and $0.26 \mathrm{eV}$ with respect to the valance band energy $\left(E_{v}\right)$, and integrated defect densities of around $10^{16} \mathrm{~cm}^{-3}$. The measured defect density for the control devices is consistently higher by roughly a factor of two than in the devices with doped $\mathrm{C}_{60}$ layers. We interpret the TAS results to indicate that the improvement in SPO for the devices containing the doped $\mathrm{C}_{60}$ layers is due to a reduction in interfacial trap density (or vacant trap density), through which nonradiative recombination can occur. Moreover, to examine the air stability of the doped $\mathrm{C}_{60}$, we measured the TAS spectra of nonencapsulated perovskite solar cells aged in dry air in the dark for $25 \mathrm{~d}(600 \mathrm{~h})$. We discovered that the trap density of the device comprising the doped $\mathrm{C}_{60}$ film increases by $27 \%$ from 0.55 to $0.75 \times 10^{16} \mathrm{~cm}^{-3}$ after aging, while the trap density in the control device increases by $35 \%$ from 0.96 to $1.3 \times 10^{16} \mathrm{~cm}^{-3}$. This suggests that the beneficial impact of the $N$-DPBI dopant is persistent, even when the cells are aged in air. This is in good agreement with previous studies identifying the air stability of the $N$-DPBI doping. ${ }^{[25-27]}$

To examine whether the $\mathrm{C}_{60}$ doping has an impact upon the device stability, we performed a $600 \mathrm{~h}$ aging test of high-performance encapsulated $\mathrm{MAPbI}_{x} \mathrm{Cl}_{3-x}$ devices with neat and doped $\mathrm{C}_{60}$ under full spectrum simulated AM1.5, $76 \mathrm{~mA} \mathrm{~cm}{ }^{-2}$ irradiance at $V_{\mathrm{OC}}$. As we show in Figure $3 \mathrm{~d}$, we observed that the devices with the doped $\mathrm{C}_{60}$ exhibit better long-term stability, in comparison with the control device in both of the $J-V$ scanned PCE and the SPO (Figure S19, Supporting Information). However, after only a week of sunlight exposure we observed a color change from dark brown to yellow. This color change is accelerated in the regions without the metal electrodes, as we show in Figure S12 in the Supporting Information. This is because of the known thermal- and photo-instability of $\mathrm{MAPbI}_{3},{ }^{[21,47-49]}$ combined with the use of the hygroscopic lithium bis-trifluoromethanesulfonimide (Li-TFSI) dopant, which we add to Spiro-OMeTAD. ${ }^{[50]}$

A fundamental issue with the $\mathrm{MAPbI}_{3}$ based perovskite is the relative volatility of methylammonium iodide (MAI), which evolves out of the film during heating, and this process is accelerated in an atmosphere containing moisture. ${ }^{[5,51-53]}$ In addition, the $\mathrm{MAPbI}_{3}$ has also been shown to degrade more rapidly when exposed to light in an atmosphere containing oxygen, due to a chemical reaction between oxygen and $\mathrm{MA}^{+}$in the presence of electronic charge in the perovskite. ${ }^{[54]}$ We have previously shown that formamidinium (FA)-based perovskites are much more thermally stable than methylammonium (MA)-based perovskite. ${ }^{[4,55]}$ One problem with $\mathrm{FAPbI}_{3}$ however is that it is not structurally stable in the black perovskite phase and undergoes a phase transition to a yellow phase at room temperature. At room temperate in an inert atmosphere, the $\mathrm{FAPbI}_{3}$ black phase can be metastable. However, exposure to moisture rapidly induces the phase transition into the yellow phase. This structural instability can be overcome by adding a fraction of MA; however, this puts the chemically unstable MA back into the perovskite. Recently, two separate works have demonstrated that adding $\mathrm{Cs}$ to the $\mathrm{FAPbI}_{3}$ can also structurally stabilize the
FA-based perovskite and specifically enhance its stability toward this black-to-yellow phase transition in humid air. ${ }^{[56,57]}$ Recently we have introduced a new perovskite composition comprising $\mathrm{FA}_{0.83} \mathrm{Cs}_{0.17} \mathrm{~Pb}\left(\mathrm{I}_{0.6} \mathrm{Br}_{0.4}\right)$, which we have already shown to work very well as a wider band gap perovskite absorber, and exhibit improved stability to halide segregation and thermal stability, as compared with $\mathrm{MAPb}\left(\mathrm{I}_{0.6} \mathrm{Br}_{0.4}\right)_{3} \cdot{ }^{[55]}$ However, as of yet we have not proven this new material to have superior long-term operational stability. For $\mathrm{FA}_{0.83} \mathrm{Cs}_{0.17} \mathrm{~Pb}\left(\mathrm{I}_{0.6} \mathrm{Br}_{0.4}\right)_{3}$ devices, we used a tin oxide $\left(\mathrm{SnO}_{2}\right) / \mathrm{C}_{60}$ double electron extraction layer, similar to that which we employed in our previous work. ${ }^{[55]}$ We note that we have introduced the additional $\mathrm{SnO}_{2}$ layer here, since for the cells comprising $\mathrm{FA}_{0.83} \mathrm{Cs}_{0.17} \mathrm{~Pb}\left(\mathrm{I}_{0.6} \mathrm{Br}_{0.4}\right)_{3}$ films, which are heated at $185{ }^{\circ} \mathrm{C}$ for $90 \mathrm{~min}$ in air, we appeared to introduce or create a charge extraction barrier at the $\mathrm{FTO} / \mathrm{C}_{60}$ interface. This barrier is eliminated with the additional $\mathrm{SnO}_{2}$ interlayer. We go into more depth on this specific point in the Supporting Information and in Figure S15 (Supporting Information).

In order to assess the long-term operational stability of $\mathrm{FA}_{0.83} \mathrm{Cs}_{0.17} \mathrm{~Pb}\left(\mathrm{I}_{0.6} \mathrm{Br}_{0.4}\right)_{3}$ solar cells, we performed similar stability measurements to above, with solar cells comprising the mix-cation lead mix-halide perovskite as the absorber layer. We also compare with a reference $\mathrm{MAPbI}_{x} \mathrm{Cl}_{3-x}$. We present the results for cells light soaked (AM1.5 full spectrum light) at $V_{\mathrm{OC}}$ in air with ambient humidity $(\approx 55 \%)$, as we show in Figure 4 and Figures S13 and S14 in the Supporting Information. We emphasize that the cells in Figure 4a are not encapsulated. The cells comprising this FA/Cs perovskite exhibit a much stronger resistance to aging under these conditions. All cells exhibit a fast degradation over the first $50 \mathrm{~h}$, with the $\mathrm{MAPbI}_{x} \mathrm{Cl}_{3-x}$ cell degrading to $\approx 0 \%$ efficiency over this time. In contrast, the FA ${ }_{0.83} \mathrm{Cs}_{0.17} \mathrm{~Pb}\left(\mathrm{I}_{0.6} \mathrm{Br}_{0.4}\right)_{3}$ cells only degrade by a few percent absolute efficiency over this time and then proceed to degrade at a much slower linear rate. ${ }^{[58,59]}$ We note that we do not want to suggest that the $\mathrm{FA}_{0.83} \mathrm{Cs}_{0.17} \mathrm{~Pb}\left(\mathrm{I}_{0.6} \mathrm{Br}_{0.4}\right)_{3}$ composition can specifically resist the degradation induced by the hydroscopic additives (i.e., Li-TFSI). But these results simply show that it is simply much more stable in general than the $\mathrm{MAPbI}_{x} \mathrm{Cl}_{3-x}$ composition. This is both thermal and moisture stability, and importantly stability to operation in the presence of oxygen. ${ }^{60,61]}$ Clearly, the next step forward is to optimize the solar cells with a more stable hole-transporter doping composition, which is a subject of ongoing study.

All solar modules degrade, with commercial modules averaging around $0.5 \%$ relative degradation in efficiency per year, indicating an $\approx 40$ year lifetime to $80 \%$ performance. ${ }^{[59]}$ However, when tested for over 20 years this degradation rate has been observed to increase. ${ }^{[59,62]}$ Nevertheless, fitting the longterm decay of the degradation to a linear function would be consistent with how degradation is expected to proceed in commercial modules. We note that an exponential fitting of lifetime data is unlikely to be representative of a true lifetime projection, since that would imply that the degradation rate progressively reduces with increasing aging time. We fit the post "burn-in" section of the power conversion efficiency to a straight line and extrapolate the curve back to zero time to obtain the $t=0$ efficiency. We determined the lifetime to $80 \%$ degradation $\left(t_{80}\right)$ from this $t=0$ post burn-in efficiency ${ }^{[63]}$ for the most stable devices to be $656 \mathrm{~h}$, and the SPO is $583 \mathrm{~h}$ for the 



Figure 4. Comparison of stability of $\mathrm{MAPbl}_{x} \mathrm{Cl} \mathrm{C}_{3-x}$ (with neat $\mathrm{C}_{60}$ ) and $\mathrm{FA}_{0.83} \mathrm{Cs}_{0.17} \mathrm{~Pb}\left(\mathrm{I}_{0.6} \mathrm{Br}_{0.4}\right)$ perovskite devices with neat (control) and 1 wt\% $\mathrm{N}$-DPBI doped $\mathrm{C}_{60}$ electron-transporting layers. The device configuration is $\mathrm{FTO} / \mathrm{SnO}_{2} / \mathrm{C}_{60}$ (neat or $7 \mathrm{wt} \%$ doped)/perovskite/spiro-OMeTAD (doped with $\mathrm{Li}$ TFSI and $t \mathrm{BP}$ )/Au. A MAPbl $\mathrm{Cl}_{3-x}$ reference device is aged for comparison. The devices were aged under full spectrum simulated AM1.5, $76 \mathrm{~mW} \mathrm{~cm}^{-2}$ average irradiance at $V_{O C}$ in air without a UV filter. The Suntest XLS + aging box irradiates pulsed light. There is an early burn-in with an exponential decay over the first $100 \mathrm{~h}$ followed by an approximate linear decay. The dashed lines in (a) and (b) are linear fits to the latter section of the decay. The time to $80 \%$ of the post burn-in decay $\left(t_{80}\right)$ of champion devices is shown on the graph (with the $t_{0}$ efficiency extrapolated back to the $y$-axis from the linear fit, as shown in Figure S20 in the Supporting Information). The devices in (a) are nonencapsulated while the ones in (b) are encapsulated with a hot-melt polymer foil and a glass coverslip.

$\mathrm{FA}_{0.83} \mathrm{Cs}_{0.17} \mathrm{~Pb}\left(\mathrm{I}_{0.6} \mathrm{Br}_{0.4}\right)_{3}$ devices comprising doped $\mathrm{C}_{60}$, which is nearly 30 times longer than the $t_{80}$ lifetime of the $\mathrm{MAPbI}_{x} \mathrm{Cl}_{3-x}$ devices. The most significant difference we observe between the control $\mathrm{FA}_{0.83} \mathrm{Cs}_{0.17} \mathrm{~Pb}\left(\mathrm{I}_{0.6} \mathrm{Br}_{0.4}\right)_{3}$ devices (comprising neat $\mathrm{C}_{60}$ ) and the devices comprising doped $\mathrm{C}_{60}$ is that the degree of the efficiency drop on burn-in is significantly lower than for the doped cells. The other important observation is that the devices with the doped $\mathrm{C}_{60}$ layer are persistently more efficient than the devices with the neat $\mathrm{C}_{60}$ layer over the entire aging window, indicating that the improvement introduced by doping of the $\mathrm{C}_{60}$ layer is stable. We note that although these cells are "nonencapsulated," the gold electrode is acting as a basic protection barrier. This is apparent in the photographs we show in Figure S12 in the Supporting Information, where we observe discoloration of the $\mathrm{FA}_{0.83} \mathrm{Cs}_{0.17} \mathrm{~Pb}\left(\mathrm{I}_{0.6} \mathrm{Br}_{0.4}\right)_{3}$ perovskite in the regions surrounding the gold electrodes. We proceed to encapsulate the devices with a hot melt polymer foil and a glass coverslip and show the stability results in Figure $4 \mathrm{~b}$ and Figure S14 in the Supporting Information. We determined a $t_{80}$ half-life of $3423 \mathrm{~h}$ and $2958 \mathrm{~h}$ for the $J-V$ measured and stabilized power output for the most stable encapsulated $\mathrm{FA}_{0.83} \mathrm{Cs}_{0.17} \mathrm{~Pb}\left(\mathrm{I}_{0.6} \mathrm{Br}_{0.4}\right)_{3}$ perovskite devices comprise $1 \mathrm{wt} \%$ doped and neat $\mathrm{C}_{60}$ charge extraction layers, respectively. We observed that the encapsulated cells comprising the neat $\mathrm{C}_{60}$ degrade further in the burn-in region, and slightly faster in the longer term decay. We show the data for the most stable cells, along with the linear fit in Figures S13 and S14 in the Supporting Information. We note that all the cells above have been stressed under open-circuit voltage conditions and the efficiency has been measured in a separate solar simulator at different periods of time, with the cells measured immediately after removing from the light soaking box. It is ideal to age cells under load, since this is the condition under which they will have to operate in real-world conditions. In addition, we and others have observed with different device architectures (for instance containing compact $\mathrm{TiO}_{2}$ charge collection layers) that the devices do degrade faster under load than at $V_{\text {oc }}$. In order to assess if this is also happening here, we stressed some cells at $V_{o c}$ and with a fixed resistive load (putting the cell close to the max power point). Encouragingly, as we show in Figure S16 in the Supporting Information, we do not observe a significant difference in the degradation rate between these cells.

We measured this degradation under constant $760 \mathrm{~W} \mathrm{~m}^{-2}$ irradiance. Therefore, the $3423 \mathrm{~h}$ under $760 \mathrm{~W} \mathrm{~m}^{-2}$ constinuous illumination, is equivalent to the solar flux which would be absorbed in the solar cell after $17343 \mathrm{~h}$, or $\approx 2$ years exposure to real world illuminations in a geographic location were the yearly average solar irradiance is $150 \mathrm{~W} \mathrm{~m}^{-2}$. This stability is therefore 
a significant achievement and a step forward, and we have not invoked any thermal acceleration factors, but it notably remains a factor of ten off the required 25 years stability. In addition, identifying the origin of and eliminating the early time degradation we observed here is required to deliver long-term stability at the highest efficiency, which is required to be commercially competitive. We note that as judged by the nonencapsulated

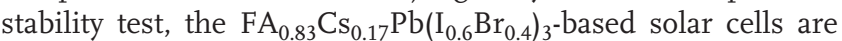
$\approx 30$ times more stable than the $\mathrm{MAPbI}_{x} \mathrm{Cl}_{3-x}$-based cells. This emphasizes that this new composition is a clear candidate for stable commercial perovskite solar cells and modules.

Before we move on to discuss our findings with respect to the details of the $n$-doping of the $\mathrm{C}_{60}$ layer, we highlight key broader aspects that these stability results imply.

1. Our perovskite cells composed of $\mathrm{p}$ and $\mathrm{n}$-doped organic charge extraction layers are reasonably stable in air (which includes oxygen and moisture) and full spectrum sun light that includes the UV component, which indicates that the perovskite solar cells (this perovskite in this architecture) are not as sensitive to these environmental stressing components as previously thought. ${ }^{[18-21,49,54,64,65]}$

2. The $\mathrm{n}$-doping of the $\mathrm{C}_{60}$ appears to have a persistent beneficial effect over prolonged operation in air, indicating that the $N$-DPBI retains its doping function throughout the ageing test.

It is clear that the FA/Cs-based perovskite is more stable that the MA-based perovskite. However, the reason why the n-doping of the $\mathrm{C}_{60}$ also additionally enhances the stability, which is especially apparent for the $\mathrm{MAPbI}_{x} \mathrm{Cl}_{3-x}$ devices, is less obvious. We believe that there are likely to be a number of factors that are result in the enhanced stability.

First, we have determined that there are fewer active trap sites in the perovskite films containing the doped $\mathrm{C}_{60}$. The degradation of the perovskite film may proceed via surface defects, and hence reducing the number of defects is very likely to positively improve the long-term stability. In addition, if these aging-induced defects are generated at the $\mathrm{C}_{60}$-perovskite heterojunction, then doping of the $\mathrm{C}_{60}$ will result in these newly generated defect sites becoming filled with electrons, and hence reduce their negative impact upon device performance.

Second, it is known that fullerene molecules can dimerize due to light exposure, and for organic photovoltaic devices, a sever burn-in is observed in the solar cell performance during aging, precisely due to this dimerization process. Heumueller et al. recently showed that this dimerization can be strongly inhibited when the fullerene is mixed with certain charge hole-conducting polymers. ${ }^{[6]}$ Our results here could also be explained by this dimerization occurring, introducing electron traps. With $\mathrm{n}$-doping, the much higher electron density in the $\mathrm{C}_{60}$ would once more fill these traps and make the impact of fullerene dimerization less severe. This points toward a clear strategy to further inhibit the severity of the burn-in, to replace $\mathrm{C}_{60}$ with $\mathrm{C}_{70}$, which does not undergo dimerization, and increase the doping density to optimize for stability, and not just initial $t=0$ efficiency.

In summary, we investigated the effects of $n$-doping of the electron accepting layer in $n-\mathrm{i}-\mathrm{p}$ planar heterojunction perovskite solar cells. The N-DPBI dopant provides a higher conductivity and reduces the work function of the $\mathrm{C}_{60}$ layer. We observed stronger and faster PL quenching from perovskite films coated upon doped $\mathrm{C}_{60}$ layers, indicating enhanced electron extraction. We also find that employing the $N$-DPBI dopant allows us to tune the surface wettability of the $\mathrm{C}_{60}$ films, which enables us to fabricate "void-free" perovskite/ $\mathrm{C}_{60}$ interfaces. Through thermal admittance spectroscopy we determined that the doped $\mathrm{C}_{60}$ reduces the defect density in the devices, which we postulate to be due to the increased electron density at the $\mathrm{C}_{60}$ /perovskite heterojunction resulting in filling of trap states at this interface. Due to these advancements, we observed a high $J_{\mathrm{SC}}$ in excess of $23 \mathrm{~mA} \mathrm{~cm}^{-2}$, FF of 0.73 , and increased stabilized power output ratio, achieving a highest $J-V$ scanned PCE of $18.3 \%$ and an SPO of $17.9 \%$ in $\mathrm{MAPbI}_{x} \mathrm{Cl}_{3-x}$ perovskite devices. We applied this doping technique to $\mathrm{FA}_{0.83} \mathrm{Cs}_{0.17} \mathrm{~Pb}\left(\mathrm{I}_{0.6} \mathrm{Br}_{0.4}\right)_{3}$ perovskite devices, achieving a post burn-in $t_{80}$ lifetime of over $600 \mathrm{~h}$ stability when aged under continuous full spectrum solar illumination in air without encapsulation, and over $3420 \mathrm{~h}$ when sealed. This represents a significant step forward to the goal of achieving high-efficiency perovskite solar cells with long-term stability compatible with commercial deployment.

\section{Supporting Information}

Supporting Information is available from the Wiley Online Library or from the author.

\section{Acknowledgements}

This work was partly funded by EPSRC, UK, the European Union Seventh Framework Program under grant agreement number 604032 of the MESO project and AFOSR through project FA9550-15-1-0115. The authors thank Prof. Christoph J. Brabec for useful discussions concerning fullerene dimerization.

Received: August 4, 2016 Revised: September 29, 2016 Published online: December 1, 2016

[1] A. Kojima, K. Teshima, Y. Shirai, T. Miyasaka, J. Am. Chem. Soc. 2009, 131, 6050

[2] M. M. Lee, J. Teuscher, T. Miyasaka, T. N. Murakami, H. J. Snaith, Science 2012, 338, 643.

[3] S. D. Stranks, G. E. Eperon, G. Grancini, C. Menelaou, M. J. P. Alcocer, T. Leijtens, L. M. Herz, A. Petrozza, H. J. Snaith, Science 2013, 342, 341.

[4] Y. Ogomi, A. Morita, S. Tsukamoto, T. Saitho, N. Fujikawa, Q. Shen, T. Toyoda, K. Yoshino, S. S. Pandey, T. Ma, S. Hayase, J. Phys. Chem. Lett. 2014, 5, 1004.

[5] J. H. Noh, S. H. Im, J. H. Heo, T. N. Mandal, S. II Seok, Nano Lett. 2013, 13, 1764.

[6] H. Oga, A. Saeki, Y. Ogomi, S. Hayase, S. Seki, J. Am. Chem. Soc. 2014, 136, 13818.

[7] N. J. Jeon, J. H. Noh, Y. C. Kim, W. S. Yang, S. Ryu, S. II Seok, Nat. Mater. 2014, 13, 1

[8] H. J. Snaith, J. Phys. Chem. Lett. 2013, 4, 3623.

[9] NREL chart, http://www.nrel.gov/ncpv/images/efficiency_charg.jpg (accessed: August 2016).

[10] M. A. Green, K. Emery, Y. Hishikawa, W. Warta, E. D. Dunlop, Prog. Photovoltaics Res. Appl. 2016, 24, 3. 
[11] O. Almora, I. Zarazua, E. Mas-Marza, I. Mora-Sero, J. Bisquert, G. Garcia-Belmonte, J. Phys. Chem. Lett. 2015, 6, 1645

[12] J. M. Azpiroz, E. Mosconi, J. Bisquert, F. De Angelis, Energy Environ. Sci. 2015, 8, 2118

[13] H. J. Snaith, A. Abate, J. M. Ball, G. E. Eperon, T. Leijtens, N. K. Noel, S. D. Stranks, J. T. W. Wang, K. Wojciechowski, W. Zhang, J. Phys. Chem. Lett. 2014, 5, 1511.

[14] E. L. Unger, E. T. Hoke, C. D. Bailie, W. H. Nguyen, A. R. Bowring, T. Heumüller, M. G. Christoforo, M. D. McGehee, Energy Environ. Sci. 2014, 7, 3690 .

[15] S. Van Reenen, M. Kemerink, H. J. Snaith, J. Phys. Chem. Lett. 2015 6, 3808.

[16] B. Wu, K. Fu, N. Yantara, G. Xing, S. Sun, T. C. Sum, N. Mathews, Adv. Energy Mater. 2015, 5, 1500829.

[17] F. J. Pern, S. H. Glick, in 26th Photovolt. Spec. Conf., IEEE, Anaheim, CA, US 1997, p. 1089,

[18] J. You, L. Meng, T.-B. Song, T.-F. Guo, Y. Michael Yang, W.-H. Chang, Z. Hong, H. Chen, H. Zhou, Q. Chen, Y. Liu, N. De Marco, Y. Yang, Nat. Nanotechnol. 2015, 11, 75.

[19] W. Li, W. Zhang, S. Van Reenen, R. J. Sutton, J. Fan, A. Haghighirad, M. Johnston, L. Wang, H. Snaith, Energy Environ. Sci. 2016, 9, 490.

[20] T. Leijtens, T. Giovenzana, S. N. Habisreutinger, J. S. Tinkham, N. K. Noel, B. A. Kamino, G. Sadoughi, A. Sellinger, H. J. Snaith, ACS Appl. Mater. Interfaces 2016, 8, 5981.

[21] D. Bryant, N. Aristidou, S. Pont, I. Sanchez-Molina, T. Chotchunangatchaval, S. Wheeler, J. R. Durrant, S. A. Haque, Energy Environ. Sci. 2016, 9, 1655.

[22] K. Wojciechowski, T. Leijtens, S. Siprova, C. Schlueter M. T. Hörantner, J. T. W. Wang, C. Z. Li, A. K. Y. Jen, T. L. Lee, H. J. Snaith, J. Phys. Chem. Lett. 2015, 6, 2399.

[23] A. Abrusci, S. D. Stranks, P. Docampo, H. L. Yip, A. K. Y. Jen, H. J. Snaith, Nano Lett. 2013, 13, 3124.

[24] P. Docampo, J. M. Ball, M. Darwich, G. E. Eperon, H. J. Snaith, Nat. Commun. 2013, 4, 2761.

[25] P. Wei, J. H. Oh, G. Dong, Z. Bao, J. Am. Chem. Soc. 2010, 132, 8852.

[26] H. Derivatives, B. D. Naab, S. Guo, S. Olthof, E. G. B. Evans, P. Wei, G. L. Millhauser, A. Kahn, S. Barlow, S. R. Marder, Z. Bao, J. Am. Chem. Soc. 2013, 135, 15018.

[27] P. Wei, T. Menke, B. D. Naab, K. Leo, M. Riede, Z. Bao, J. Am. Chem. Soc. 2012, 134, 3999.

[28] J. H. Oh, P. Wei, Z. Bao, Appl. Phys. Lett. 2010, 97, 243305.

[29] S. S. Kim, S. Bae, W. H. Jo, Chem. Commun. 2015, 51, 17413

[30] T. Leijtens, G. E. Eperon, S. Pathak, A. Abate, M. M. Lee, H. J. Snaith, Nat. Commun. 2013, 4, 2885.

[31] R. A. Schlitz, F. G. Brunetti, A. M. Glaudell, P. L. Miller, M. A. Brady, C. J. Takacs, C. J. Hawker, M. L. Chabinyc, Adv. Mater. 2014, 26 2825.

[32] W. Xu, T. S. Lim, H. K. Seo, S. Y. Min, H. Cho, M. H. Park, Y. H. Kim, T. W. Lee, Small 2014, 10, 1999.

[33] B. Maennig, M. Pfeiffer, a. Nollau, X. Zhou, K. Leo, P. Simon, Phys. Rev. B 2001, 64, 1

[34] S. D. Ha, A. Kahn, Phys. Rev. B 2009, 80, 195410.

[35] N. R. Armstrong, P. A. Veneman, E. Ratcliff, D. Placencia, M. Brumbach, Acc. Chem. Res. 2009, 42, 1748.

[36] J. P. Lee, Y. J. Jang, M. M. Sung, Adv. Funct. Mater. 2003, 13, 873.

[37] S. Onclin, B. J. Ravoo, D. N. Reinhoudt, Angew. Chem. Int. Ed. 2005, 44, 6282.

[38] C. Bi, Y. Shao, Y. Yuan, Z. Xiao, C. Wang, Y. Gao, J. Huang, J. Mater. Chem. A 2014, 2, 18508.

[39] C. Bi, Q. Wang, Y. Shao, Y. Yuan, Z. Xiao, J. Huang, Nat. Commun. 2015, 6, 7747
[40] J. Lian, Q. Wang, Y. Yuan, Y. Shao, J. Huang, J. Mater. Chem. A 2015 3, 9146.

[41] M. Christoforo, E. Hoke, M. McGehee, E. Unger, Photonics 2015, 2, 1101.

[42] W. Ke, G. Fang, J. Wang, P. Qin, H. Tao, H. Lei, Q. Liu, X. Dai, X. Zhao, ACS Appl. Mater. Interfaces 2014, 6, 15959.

[43] Y. Shao, Z. Xiao, C. Bi, Y. Yuan, J. Huang, Nat. Commun. 2014, 5, 1.

[44] J. Xu, A. Buin, A. H. Ip, W. Li, O. Voznyy, R. Comin, M. Yuan, S. Jeon, Z. Ning, J. J. McDowell, P. Kanjanaboos, J.-P. Sun, X. Lan, L. N. Quan, D. H. Kim, I. G. Hill, P. Maksymovych, E. H. Sargent, Nat. Commun. 2015, 6, 7081.

[45] T. Kirchartz, W. Gong, S. a. Hawks, T. Agostinelli, R. C. I. MacKenzie, Y. Yang, J. Nelson, J. Phys. Chem. C 2012, 116, 7672.

[46] H.-S. Duan, H. Zhou, Q. Chen, P. Sun, S. Luo, T.-B. Song, B. Bob, Y. Yang, Phys. Chem. Chem. Phys. 2014, 17, 112.

[47] A. M. A. Leguy, Y. Hu, M. Campoy-Quiles, M. I. Alonso, O. J. Weber, P. Azarhoosh, M. van Schilfgaarde, M. T. Weller, T. Bein, J. Nelson, P. Docampo, P. R. F. Barnes, Chem. Mater. 2015, 27, 3397.

[48] G. E. Eperon, S. D. Stranks, C. Menelaou, M. B. Johnston, L. M. Herz, H. J. Snaith, Energy Environ. Sci. 2014, 7, 982.

[49] N. Aristidou, I. Sanchez-Molina, T. Chotchuangchutchaval, M. Brown, L. Martinez, T. Rath, S. A. Haque, Angew. Chem. Int. Ed. 2015, 54, 8208.

[50] J. M. Frost, K. T. Butler, F. Brivio, C. H. Hendon, M. Van Schilfgaarde, A. Walsh, Nano Lett. 2014, 14, 2584.

[51] C. C. Stoumpos, C. D. Malliakas, M. G. Kanatzidis, Inorg. Chem. 2013, 52, 9019

[52] B. Conings, J. Drijkoningen, N. Gauquelin, A. Babayigit, J. D'Haen, L. D'Olieslaeger, A. Ethirajan, J. Verbeeck, J. Manca, E. Mosconi, F. De Angelis, H. G. Boyen, Adv. Energy Mater. 2015, 5, 1500477.

[53] R. K. Misra, S. Aharon, B. Li, D. Mogilyansky, I. Visoly-Fisher, L. Etgar, E. A. Katz, J. Phys. Chem. Lett. 2015, 6, 326.

[54] A. J. Pearson, G. E. Eperon, P. E. Hopkinson, S. N. Habisreutinger, J. T.-W. Wang, H. J. Snaith, N. C. Greenham, Adv. Energy Mater. 2016, 6, 1600014

[55] D. P. McMeekin, G. Sadoughi, W. Rehman, G. E. Eperon, M. Saliba M. T. Horantner, A. Haghighirad, N. Sakai, L. Korte, B. Rech, M. B. Johnston, L. M. Herz, H. J. Snaith, Science 2016, 351, 151.

[56] M. Saliba, T. Matsui, J.-Y. Seo, K. Domanski, J.-P. Correa-Baena, M. K. Nazeeruddin, S. M. Zakeeruddin, W. Tress, A. Abate, A. Hagfeldt, M. Grätzel, Energy Environ. Sci. 2016, 9, 1989.

[57] A. Amat, E. Mosconi, E. Ronca, C. Quarti, P. Umari, M. K. Nazeeruddin, M. Gratzel, F. De Angelis, Nano Lett. 2014, 14, 3608.

[58] W. R. Mateker, I. T. Sachs-Quintana, G. F. Burkhard, R. Cheacharoen, M. D. McGehee, Chem. Mater. 2015, 27, 404.

[59] D. C. Jordan, S. R. Kurtz, Prog. Photovoltaics Res. Appl. 2013, 21, 12.

[60] J. W. Lee, D. H. Kim, H. S. Kim, S. W. Seo, S. M. Cho, N. G. Park, Adv. Energy Mater. 2015, 5, 1501310.

[61] C. Yi, J. Luo, S. Meloni, A. Boziki, N. Ashari-Astani, C. Grätzel, S. M. Zakeeruddin, U. Röthlisberger, M. Grätzel, Energy Environ. Sci. 2016, 9, 656 .

[62] E. D. Dunlop, D. Halton, H. a. Ossenbrink, in 31st IEEE Photovolt. Spec. Conf., IEEE, Coronado, FL, USA 2005, p. 1982.

[63] C. H. Peters, I. T. Sachs-Quintana, J. P. Kastrop, S. Beaupré M. Leclerc, M. D. McGehee, Adv. Energy Mater. 2011, 1, 491.

[64] K. Leo, Nat. Nanotechnol. 2015, 10, 574.

[65] S. Yang, Y. Wang, P. Liu, Y.-B. Cheng, H. J. Zhao, H. G. Yang, Nat. Energy 2016, 1, 15016.

[66] T. Heumueller, W. R. Mateker, A. Distler, U. F. Fritze, R. Cheacharoen, W. H. Nguyen, M. Biele, M. Salvador, M. von Delius, H.-J. Egelhaaf, M. D. McGehee, C. J. Brabec, Energy Environ. Sci. 2016, 9, 247. 